\title{
Survey as Research Design for Medical and Allied Health Care Professionals
}

\author{
Pooja Chaudhuri' ${ }^{1}$ Aksh Chahal' ${ }^{2}$, Nitesh Malhotra $^{3}$ \\ ${ }^{1}$ Associate Professor, Department of Physiotherapy University of Science and Technology, Meghalaya, India, \\ ${ }^{2}$ Professor, MM Institute of Physiotherapy and Rehabilitation, Maharishi Markandeshwar (Deemed to be \\ University), Ambala, Haryana, India, ${ }^{3}$ Assistant Professor, Amity Institute of Physiotherapy, Amity University, \\ Uttar Pradesh, India
}

\begin{abstract}
Formally speaking, survey means encapsulating information from respondents by direct or indirect means (person to person, telephonic, post and electronic communication). Survey as method of extracting information form population (small or large) to study various health issues and its associated factors play an important mode in healthcare clinical practice and research domain. Nearly, all fields under the umbrella of healthcare are making use of surveys as their study design to extract the desired information via optimum method of performing a survey to their best for analyzing, devising and implementing associated health care policies.Surveys are being used in increasing number as they provide benefits to researchers, in contrast, it also posses certain setbacks which are greatly impactful if a less potential method of survey is chosen for a specific arena if its associated pit falls are ignored. Surveys when used in medical fraternity are generally classified as Epidemiological, Health delivery service and Questionnaire surveys.
\end{abstract}

Keywords: Healthcare, Professionals, Survey, Research, Questionnaire.

\section{Introduction}

Formally speaking, survey means encapsulating information from respondents by direct or indirect means (person to person ${ }^{1}$, telephonic ${ }^{2}$, post $^{3}$ and electronic communication) ${ }^{4,5}$. Survey as method of extracting information form population (small or large) to study various health issues and its associated factors play an important mode in healthcare clinical practice and research domain ${ }^{(6,7)}$. Nearly, all fields under the umbrella of healthcare are making use of surveys as their study design to extract the desired information via optimum method of performing a survey to their best for analyzing, devising and implementing associated health

\section{Corresponding Author:}

Nitesh Malhotra

Assistant Professor, Amity Institute of Physiotherapy, Amity University, Uttar Pradesh, India

e-mail: malhotra.nitesh@gmail.com care policies ${ }^{8}$. Surveys are being used in increasing number as they provide benefits to researchers, in contrast, it also posses certain setbacks which are greatly impactful if a less potential method of survey is chosen for a specific arena if its associated pit falls are ignored. Surveys when used in medical fraternity are generally classified as Epidemiological, Health delivery service and Questionnaire surveys?.

In the current article, the authors aim to throw light on issues in contest to:

1. Fabricating a survey.

2. Formulation of a questionnaire with basic guidelines.

3. Role of Pilot study in facilitating efficiency of a survey.

4. Benefit and shortfalls of different modes of survey.

1. Fabricating a survey: The most vital aspect to be kept in mind while planning a survey is "What is the researcher looking for"/“What information does the researcher want to procure from his respondents". 
When this aspect is clearly defined in there searcher's mind, it enables emergence of questions focused in the concerned area which the researcher commences to document in the form of a 'Questionnaire'. Any confusion regarding the proximities of the topic to be studied will lead to unnecessary installation of either irrelevant or excessive number of questions in the questionnaire leading to unwanted deviation from the topic finally complicating the research process and producing unfruitful results.

2. Formulation of a questionnaire: In research when planning a questionnaire for survey as a study design, a researcher has two options:

A. To use a reliable and validated questionnaire: Using a validated questionnaire brings ease to researcher in many ways. Firstly, the validated questionnaire exhibit favorable question, minimal exfoliates negligible topographical errors etc. Secondly, as the questionnaire has been used already in one population, the same questionnaire when used in different population provides with significant comparison or disguised in conclusion. Finally, if the researcher seeks hurry to perform a survey in a short span of time, it is greatly advised to use anal ready validated questionnaire as validating questionnaire usually is a time consuming process 9 .

B. Designing a new questionnaire: If a researcher plans to design a new questionnaire, many aspects have to be kept in mind right from the beginning process to the final implementation in the population. When documenting questions to be asked in a survey, researcher should prioritize and imply basic requirements for the optimum gathering of information from their respondents. After all these considerations are fulfilled, the final step should be validation of the questionnaire.

\section{Basic guidelines while designing a questionnaire for survey:}

- All questions should be framed in focused direction to procure exact information.

- Educational background of the population to be studied should be given prior most importance. Individuals with high to medium degrees can diversify in terms of mental engagements while responding to the questionnaire, whereas when studying people with low educational background, set of question in the questionnaire should be put to their simplest form.
- Any possible question, even with a slight predicting attitude to confuse the respondent, should not be inducted in the questionnaire.

- Vital questions should be documented in the beginning followed by questions of descending importance ${ }^{6}$.

- Questions related to demographic information should be asked in last.

- Locally adhered terminologies should be used so as to prevent respondents from getting confused and preventing them from not responding to the questionnaire. Even if one question is left unanswered due to any reasons, shall lead to dropout and that particular questionnaire cannot be used for analysis ${ }^{9}$.

- Short sentences, pictorials and diagrams (if possible) etc should be used.

- Use of long sentences should be kept at minimal as these produce high risk of creating confusion among respondents.

- Use of multiple and bright colors should be instituted in the form of pictures, diagrams or statements to make the questionnaire vibrant, hence catching eyes of respondents, hence getting visually attracted to questionnaire may make them feel happy and promotes active participation towards the survey ${ }^{1}$.

- Questions in relation to privacy, affection, habits etc should be discussed inlater phase of the questionnaire as in the beginning it's important for a researcher to gain respondent's trust rather than directly jumping on sensitive questions making the respondent feel uneasy and reluctant to answer for the same and leaving the questionnaire incomplete. This systematic procedure greatly accelerates the quality and quantity of information procured. Any incomplete questionnaire shall not be considered for statistical analysis leading to misinterpretation of results.

- Researcher should incorporate only optimum number of questions with concentration on quality and quantity of information.

- All questions with the aim to abstract associated information should be numbered in close proximity as it helps respondents to answer the nearly associated questions in a flow as respondents respond with deeper aspect and concentration, rather haphazardly arranged 
questions, confuse, distract and crate lack of interest in answering the survey.

Role of Pilot study in facilitating efficiency survey: A pilot study should be considered as an important aspect before commencing a survey on a large sized population. Pilot study enables professionals with various benefits:

- Making necessarily corrections in the questionnaire.

- Checking spelling mistakes ${ }^{10}$.

- Disarrangement of sequence for questions.
- Analyzing attitude of respondents towards questions.

- Attitude towards sensitive questions(if any).

- Need of modification in question language and series.

These alterations when executed in the early stage and on a small population help researcher when the same study is performed on a larger population with clarity in mind from absence of pitfalls from the questionnaire point of view and thus the researcher main focuses on data analysis for concluding with results.

\section{Benefits and shortfall of different modes of survey:}

\begin{tabular}{|c|c|c|}
\hline Mode of Survey & Benefits & Pitfalls \\
\hline Person to Person & $\begin{array}{l}\text { - Easy motivating individuals to be a part of survey. } \\
\text { - On the spot classification of any doubt in contest to the } \\
\text { questionnaire. } \\
\text { - Institution of AND on-monetary and monetary } \\
\text { benefits. } \\
\text { - Personal contact between researcher and respondent } \\
\text { delivers quality and accuracy in answering the } \\
\text { questions. }\end{array}$ & $\begin{array}{l}\text { - Expensive than all other modes of survey. } \\
\text { - Reluctance in answering sensitive questions. } \\
\text { - Time consuming. } \\
\text { - Large man force required if greater number of } \\
\text { population is to be covered. }\end{array}$ \\
\hline Telephonic & $\begin{array}{l}\text { - Higher rate in response to sensitive questions as } \\
\text { respondents that the surveyor does not recognize them } \\
\text { in personal. } \\
\text { - Less expensive than Person to Person method. } \\
\text { - Easy cover a wider population. }\end{array}$ & $\begin{array}{l}\text { - Higher rate of non response as a whole as people } \\
\text { tap down the phone if not interested. } \\
\text { - No means of easily convincing respondents to } \\
\text { participate in the survey. }\end{array}$ \\
\hline By Post & $\begin{array}{l}\text { - Impactful in covering diverse populations at single go. } \\
\text { - Cost efficient if nearby population is studied. }\end{array}$ & $\begin{array}{l}\text { - Expensive } \\
\text { - Time consuming as it involves extensive } \\
\text { arrangement of items to be delivered and items } \\
\text { received from respondents. } \\
\text { - High rate of non response. }\end{array}$ \\
\hline $\begin{array}{l}\text { Electronic } \\
\text { Communication }\end{array}$ & $\begin{array}{l}\text { - Least expensive from all modes used for survey. } \\
\text { - Easy compilation of information filled by respondents. } \\
\text { - Faster analysis of data. }\end{array}$ & $\begin{array}{l}\text { - High rate of non response. } \\
\text { - Mandatory internet connection. }\end{array}$ \\
\hline
\end{tabular}

Analysis: Data received on completion of survey should be analyzed using respective statistical test for which $\mathrm{s}$ is always advised to have an experienced statistician right from day 1 , as he/she is involved in steps from formulation, implementation and analysis of data. The mode of data analysis should be planned right from the beginning of designing of the survey. Data to be arranged in the form of tables with rows and columns should be well posturized before the final formatting of questions in the questionnaire. Data from telephonic and electronic communication can be easily compiled and put to analysis while data from person to person and telephonic survey needs time to input and arranged for data analysis. Test for significance relevant to the survey are expressed by the statistician to represent results in the best projective and expressive direction.

\section{Conclusion}

Survey in research is a method of excellence to gather information directly or indirectly from respondents if performed in a systematic manner. While planning 
a survey, benefits and pitfalls of the selected method should be prioritized to move in the right direction to deliver accurate results after analysis of data.

Ethical Clearance: Not Applicable

Source of Funding: Self

\section{Conflict of Interest: Nil}

\section{Reference}

1. Mahon-Haft TAet al. Does visual appeal matter? Effects of web survey aesthetics on survey quality. Surv Res Method 2010;4:43-59.

2. Groves. RMet al. Survey. Methodology. Hoboken, NJ, John Wiley \& Sons;2004.

3. Edwards PJ et al. Method to increase response to postal and electronic questionnaires. Cochrane Database Syst Rev 2009.

4. Dillman, DA et al. Internet, Mail and Mixed-Mode
Surveys: The Tailored Design Method. New York: John Wiley \& Sons; 2009.

5. Greenlaw Cet al. A comparison of web -based and paper-based survey method: testing assumptions of survey mode and response cost. Eval Rev. 2009; 33:464-480.

6. Jones TLet al. A quick guide to survey research. Ann R Coll Surg Engl 2013; 95:5-7.

7. Safdar Net al. Research Method in Healthcare Epidemiology: Survey and Qualitative Research. Infect Control Hosp Epidemiol. 2016 November; 37(11): 1272-1277.

8. Jones $\mathrm{D}$ et al. An introductory guide to survey research in anesthesia. Anaesth Intensive Care 2006; 34: 245-253.

9. Alderman AKet al. Survey research. Plast Reconstr Surg 2010; 126:1, 381-1,389.

10. Van Teijlingen ERet al . The importance of pilot studies. Social Research Update 2001;35. 